\title{
Analisis Strategi Online Consumer Relationship Management Pada Produk Pisau Cukur Banner
}

\author{
Admiral Budi Bramastra \\ Departemen Ilmu Komunikasi, Universitas Airlangga, Jalan Airlangga 4-6, Indonesia. \\ Email: Bram.admiral @gmail.com
}

\begin{abstract}
A B S T R A C T
This research uses a qualitative research approach with descriptive type and uses in-depth interviews as primary data in research data collection. This research is important because along with the digital transformation that is developing, marketing is now experiencing a development from transactional to marketing on a relationship basis. The use of various marketing tools to manage customer relationships such as Instagram and Whatsapp can also help to maintain customer relationships because this complete the customer's culture. The result of this research is an online CRM strategy built by Banner using artificial intelligence/chatbot to be able to manage relationships with customers. PT. AWP as the manager of the Banner product uses an online CRM program called Siska to be able to manage relations with customers
\end{abstract}

Keywords: Online CRM; Subscriptions; Marketing Communications; Customer Relations

\section{A B S T R A C T}

Penelitian ini menggunakan pendekatan penelitian kualitatif dengan tipe deskriptif dan menggunakan wawancara mendalam sebagai data primer dalam pengumpulan data penelitian. Penelitian ini penting dilakukan karena seiring dengan adanya transformasi digital yang sedang berkembang, pemasaran saat ini mengalami perkembangan dari transaksional menjadi pemasaran dengan basis hubungan (relations). Penggunaan berbagai alat pemasaran untuk mengelola hubungan dengan pelanggan seperti Instagram dan Whatsapp juga dapat membantu pengelolaan hubungan dengan pelanggan karena hal ini melengkapi budaya pelanggan. Hasil dari penelitian ini adalah strategi online CRM yang dibangun Banner menggunakan artificial intelligence/chatbot yang disesuaikan dengan perilaku dari target market dan pelanggannya untuk dapat mengelola hubungan baik dengan pelanggan. PT. AWP sebagai pengelola produk Banner menggunakan salah satu program online CRM bernama Siska untuk dapat melakukan pengelolaan hubugan dengan pelanggan

Kata kunci : Online CRM; Berlangganan; Marketing Communications; Customer Relations

\section{A. PENDahuluan}

Fokus dalam penelitian ini adalah strategi online Customer Relationship Management (CRM) pada produk pisau cukur Banner. Penelitian ini dilakukan untuk mengetahui bagaimana produk pisau cukur Banner yang dikelola oleh PT. Anugerah Wajah Pria (AWP) melakukan pengelolaan hubungan pada pelanggan-pelangganya. Seiring dengan adanya transformasi digital yang sedang berkembang, pemasaran saat ini mengalami perkembangan dari transaksional menjadi pemasaran dengan basis hubungan (relations). Perkembangan transaksi dengan konsumen berubah dari transaksi linear menjadi hubungan yang kontinu dan saling berhubungan dengan pelanggan (Rangkuti, 2006). Sehingga saat ini banyak perusahaan memiliki sistem penjualan yang mengutamakan hubungan dengan pelanggan.

PT. AWP adalah perusahaan yang memproduksi pisau cukur dan menjualnya dengan menggunakan sistem berlangganan. Mereka memberi nama produknya Banner. Mereka memperjualbelikan produknya secara online di website Bannershave.com sebagai wadah untuk berlangganan pisau cukur tersebut. Direktur Utama PT. AWP, Pandji Setianto (2019) mengatakan bahwa target market produk pisau cukur Banner adalah laki-laki generasi milenial khususnya pada 
rentang umur 25-34 tahun. Target market ini dipilih karena pada rentang umur tersebut sudah banyak yang merasakan berbagai produk pisau cukur sebelumnya dan memiliki berbagai pengalaman positif dan negatif. Generasi milenial yang juga bisa disebut sebagai generasi $\mathrm{Y}$ atau "Echo Boomers" merupakan generasi yang lahir pada kurun waktu antara 1980an hingga 2000an (Faiza \& Firda, 2018).

Generasi milenial yang lahir di masa berkembangnya teknologi internet membuat mereka seringkali menggunakan internet, khususnya media sosial untuk mencari informasi sebelum melakukan pembelian suatu jasa atau produk (Hidayatullah et al., 2018). Konsistensi dan loyalitas dari generasi milenial ini pun hanya pada barang-barang bermerk yang sudah terkenal (Avisha, 2018). Pernyataan ini menjadi tantangan bagi PT. AWP karena mereka menawarkan sebuah produk pisau cukur baru yakni Banner yang belum banyak dikenal oleh target market millenials, sehingga diperlukan usaha untuk menjual dan mendapatkan kepercayaan, loyalitas, juga konsistensi pelanggan. Pisau cukur Banner yang dijual secara online dengan menggunakan sistem berlangganan, harus bisa bersaing dengan produk pisau cukur lainnya yang sudah lebih dahulu masuk ke dalam dunia bisnis pisau cukur. Mengingat perilaku target market mereka merupakan generasi milenial, PT. AWP harus membangun nama brand yang kuat dan terkenal supaya sesuai dengan perilaku mereka.

PT. AWP memproduksi pisau cukur Banner dengan target market laki-laki berusia 25-34 tahun, mereka melakukan penjualan secara online pada web bannershave.com dan memberlakukan sistem langganan sehingga pelanggan membayar setiap bulannya. Ada suatu gap disini mengenai target market yang mereka tuju yaitu laki-laki dari generasi milenial dengan rentang usia 25-34 tahun. Perilaku konsumen tersebut jika digabungkan dari apa yang dibahas sebelumnya pada artikel yang ditulis oleh (Rinda, 2015), mereka menginginkan pelayanan yang cepat tanpa perlu banyak bicara, to the point dalam berbelanja, instant online buying, dan sedikit yang memberikan perhatian pada kategori kecantikan wajah dibanding kategori- kategori belanja lainnya di online market. Selain itu, sistem penjualan berlangganan PT. AWP yang memiliki relevansi dengan CRM memunculkan fenomena menarik, yakni bagaimana perusahaan mampu bersaing dengan produk Gilette yang sudah terlebih dahulu ada, untuk menjadi top of mind dari produk pisau cukur dengan menggunakan sistem berlangganan serta dapat mengelola hubungan dengan pelanggan-pelanggan mereka.

PT. AWP membuat beberapa keputusan penjualan yang berbeda dengan perilaku konsumen target marketnya. Pertama, dari apa yang tertulis pada web bannershave.com mereka menjual produknya secara online dan bekerjasama menggunakan jasa pengiriman RPX yang memakan waktu pengiriman 2-3 hari dari waktu barang masuk ke data pengiriman RPX. Hal ini bertolak belakang dan tidak sesuai dengan apa yang dikatakan oleh (Sarwono, 2018) bahwa generasi milenial memiliki perilaku instant online buying. Pengiriman dengan menggunakan RPX tersebut memakan waktu yang cukup lama dibanding dengan instant online buying dimana barang bisa sampai pada tujuan dihari yang sama dengan pemesanan. Kedua, generasi milenial merupakan generasi yang tidak loyal dan tidak konsisten terhadap barang bermerek yang tidak terkenal (Avisha, 2018). Namun PT. AWP tetap memiliki pelanggan-pelanggan yang loyal, dilihat dari pelanggan-pelanggan mereka pada website bannershave.com yang sudah menjadi pelanggan semenjak Oktober 2017. Terakhir, PT. AWP memilih untuk menjual produk pisau cukur yang termasuk dalam kategori kecantikan wajah atau dikenal dengan istilah "men's grooming" yang mana kategori produk ini adalah kategori yang paling sedikit diminati oleh laki-laki. Akan tetapi, hingga saat ini perusahaan tersebut tetap bisa bertahan dengan peminatnya yang sedikit. Sehingga 
bagaimana PT. AWP yang memilih produk pisau cukur Banner sebagai brand mereka dan penjualan dengan sistem berlangganan dapat mengelola hubungan dengan pelanggannya yang memiliki berbagai perilaku yang tidak sesuai atau bertolak belakang dengan perilaku target marketnya yakni generasi milenial terutama laki-laki berumur 25-34 tahun.

Dari berbagai penjabaran fenomena sebelumnya, PT. AWP tetap bisa berjalan dengan baik. Dari testimoni, terlihat adanya kemudahan dan kepraktisan yang dirasakan oleh pelanggan dan mereka puas akan hal tersebut. Fenomena hubungan baik dengan pelanggan berkaitan dengan customer relationship management (CRM), CRM adalah kegiatan menjalin hubungan dengan pelanggan dan memberikan pelayanan yang baik sehingga dapat memuaskan pelanggan (Priansa, 2017).

CRM berkembang pada penggunaanya dengan menambahkan perangkat-perangkat online pada konsep CRM yang dapat digunakan untuk mempermudah menjangkau dan menjalin hubungan dengan pelanggan. Istilah ini pun dikenal dengan online CRM atau e-CRM. Penggunaan online CRM ini penting untuk mengelola hubungan dengan pelanggan di era sekarang yang membutuhkan tanggapan serba cepat. Konsep online CRM ini bukan hanya tentang penggunaan teknologi dan database saja namun juga melengkapi budaya pelanggan (Chafey \& Smith, 2008). Salah satunya adalah budaya penggunaan internet dan ponsel pintar yang seringkali terlihat, tentunya budaya ini juga menuntut penggunaan konsep CRM untuk mempermudah menjaga hubungan dengan pelanggan. Fenomena online CRM untuk mengelola hubungan dengan pelanggan saat ini juga sudah banyak dilakukan oleh berbagai perusahaan.

Berangkat dari fenomena permasalahan mengenai kecenderungan perilaku konsumen target market produk pisau cukur Banner yang diproduksi oleh PT. AWP, cara penjualannya dengan menggunakan sistem berlangganan, kemudian online marketing communication khususnya dalam bidang promosi yang dilakukan oleh perusahaan, dan penggunaan online CRM pada berbagai perusahaan yang sudah melakukannya terlebih dahulu serta penggunaannya untuk merespon berbagai kritik, saran, dan testimoni dari pelanggan. Penelitian dengan topik analisis strategi online CRM PT. AWP pada produk pisau cukur Banner menjadi berguna dan penting untuk diteliti agar menjadi referensi bagi berbagai perusahaan dan pembelajaran dalam ranah ilmu komunikasi. Agar nantinya memiliki referensi dan analisa mengenai strategi online CRM untuk mengelola hubungan dan mengembangkan pelanggan.

Maka dari itu penelitian ini menggunakan metode penelitian kualitatif dengan tipe penelitian deskriptif dan menggunakan teknik pengumpulan data in-depth interview agar mendapatkan informasi lebih mendalam dari pihak perusahaan dan konsumen yang menjadi subyek peneliti, disertakan pula observasi untuk mendapatkan validasi pengumpulan data dan triangulasi data. Sehingga pada akhirnya peneliti dapat memberikan temuan dari fenomena permasalahan perusahaan tersebut yang dapat berguna bagi perusahaan lainnnya sebagai referensi untuk pengelolaan hubungan dengan konsumen-konsumen mereka.

\section{B. METODE}

Metodologi dalam penelitian ini menggunakan pendekatan kualitatif dengan tipe penelitian deskriptif, serta menggunakan metode penelitian studi kasus. Studi kasus adalah studikasus menurut Halim dalam Deny Satriawan dalam buku yang ditulis oleh (Fitrah \& Luthfiyah, 2017) studi kasus adalah suatu penelitian yang dilaksanakan secara intensif dan mendalam terhadap suatu organisasi atau gejala tertentu. Studi kasus bertujuan untuk menambah pengetahuan mengenai peristiwa, terutama dalam hal ii adalah peristiwa komunikasi (Daymon \& Holloway, 2002). 
Peneliti menggunakan teknik pengumpulan data dengan in-depth interview kepada pihak internal perusahaan, kemudian wawancara kepada pelanggan Banner, dan menggunakan observasi di perusahaan pengelola Banner.

\section{HASIL DAN PEMBAHASAN}

\section{Online Marketing Communications Banner}

Berdasarkan hasil temuan data, online marketing communication yang digunakan oleh Banner yang dikelola oleh PT. AWP merupakan cara untuk memberikan pemahaman dan memperkenalkan produk kepada target pasar dengan menggunakan media-media online. Hal ini juga sesuai dengan yang dikatakan (Strauss \& Frost, 2014) bahwa Online Marketing Communication merupakan penggunaan berbagai teknologi informasi untuk aktivitas pemasaran dan komunikasi.

Terdapat pergeseran bauran pemasaran dalam marketing dari 4P ke 4C. Konsep 4P dikritik karena masih berfokus pada produk, sementara saat ini juga dibutuhkan konsep pemasaran yang berbasis pada pelanggan (customer) (D.A.S et al., 2016). Salah satu elemen dalam 4C adalah komunikasi. Dalam perspektif ini, umumnya dilakukan oleh perwakilan dari perusahaan untuk dapat melakukan komunikasi dengan pelanggan. Mereka dapat melakukan berbagai aktivitas promosi dan komunikasi dengan pelanggan yang membahas mengenai manfaat dan apa yang dibutuhkan oleh pelanggan (D.A.S et al., 2016). Aktivitas promosi yang dilakukan oleh PT. AWP adalah pemasaran langsung (direct marketing) kepada target market dan penjualan personal (Personal selling) kepada pelanggan. Direct marketing dan personal selling sama-sama membutuhan perwakilan (sales representative) dalam membantu praktik dua hal tersebut. Karena saat ini, promosi bisa direspon langsung oleh konsumen atau pelanggan dan mereka juga bisa langsung berbicara mengenai produk yang dipromosikan kepada perusahaan yang menjadi produsen (Armstrong \& Kotler, 2012). Sehingga pendekatan dari dua hal ini bisa dibantu dengan artificial intellegence.

Dalam era marketing 4.0 pendekatan dengan target market bisa dilakukan dengan bantuan dari mesin atau artificial intelligence untuk meningkatkan produktivitas dan memberikan manfaat meningkatkan hubungan dan proses interaksi antar manusia (Armstrong \& Kotler, 2012). Pernyataan ini selaras dengan apa yang dilakukan oleh PT. AWP yang memanfaatkan teknologi dari Facebook Manager Ads dalam membantu mempromosikan produk Banner. Tak hanya itu, saat ini teknologi seperti e-commerce juga membantu perusahaan untuk mempromosikan produk mereka. Penggunaan teknologi artificial intelligence ini digunakan untuk dapat meningkatkan produktivitas dari aktivitas promosi serta meningkatkan penjualan. Itulah mengapa mereka menggunakan online marketing communications dengan menggunakan sosial media seperti aplikasi Whatsapp dan Instagram.

Online marketing communications sebagai alat promosi suatu perusahaan dapat dibantu dengan artificial intelligence. Promosi perlu dilakukan untuk memenuhi tujuan-tujuan promosi seperti yang dikatakan oleh (Armstrong \& Kotler, 2012). Promosi-promosi ini dilakukan dengan menggunakan direct marketing dan personal selling. Untuk mempraktikan hal tersebut diperlukan seorang perwakilan perusahaan (sales representative) yang dapat menjembatani antara perusahaan dan pelanggan. Sehingga diperlukan seseorang untuk dapat mengelola hubungan dengan pelanggan (customer relations).

\section{Customer Relations untuk Membangun Online CRM Banner}


Customer relations penting untuk membantu mencapai tujuan promosi. Dengan mencapai tujuan promosi, proses online CRM pun dapat dilakukan dengan mengelola hubungan baik dengan pelanggan-pelanggan perusahaan. Banyak perusahaan yang saat ini menggunakan customer service dengan konsep mobile communications. Mereka juga memadukan artificial intelligence atau chatbot sebagai medium yang digunakan untuk dapat melakukan komunikasi dan mengelola hubungan dengan pelanggan yang dapat disebut dengan online Customer Relationship Management (CRM).

Artificial intelligence atau chatbot telah membuat sebuah popularitas dalam dunia marketing menurunkan usaha manusia untuk melakukan pelayanan dan menggantinya dengan pelayanan yang otomatis. Saat ini, chatbot sudah menjadi sebuah fundamental tools yang membantu untuk meningkatkan customer engagement dan customer retention dalam sebuah customer service (Gambhir, 2019). PT. AWP juga menerapkan customer service dengan menggunakan konsep mobile communications dan memadukan artificial intelligence atau chatbot sebagai medium yang digunakan untuk dapat melakukan komunikasi dan mengelola hubungan dengan pelanggan yang dapat disebut dengan online customer relationship management (CRM) dari awal mereka berdiri.

Penerapan customer service dengan konsep mobile communications dan memadukan artificial intelligence atau chatbot ini dilakukan dengan menggunakan aplikasi Whatsapp dan Line. Customer service perlu dikembangkan dalam berbagai hal, menurut (Terziev et al., 2018). salah satunya adalah interaksi dengan pelanggan. Penggunaan customer serivce dengan konsep mobile communications tak hanya membuat pelanggan mudah untuk menghubungi customer service secara virtual dimanapun keberadaan mereka. Tapi juga memberikan efek sebaliknya yakni kemudahan bagi perusahaan untuk menghubungi pelanggan, internet telah meningkatkan aksesibilitas dari customer service (Meyer \& Gremler, 2015). Begitupun dengan PT. AWP yang melakukan pengembangan pada customer servicenya, khususnya pada interaksi pelanggan dengan menggunakan program online CRM bernama Siska.

PT. AWP membuat sebuah program online CRM berbentuk sebuah persona yang bernama Siska yang merupakan kepanjangan dari Sistem Kepuasan Banner/Anda. Siska ini adalah sebuah sistem persona yang bertugas untuk membalas pesan-pesan yang masuk ke Whatsapp dan Line Banner dan juga menjadi palang pintu pertama bagi perusahaan untuk mendapatkan feedback dari para pelanggan. Siska bisa dikatakan sebagai sebuah artificial intelligence atau chatbot yang bertugas untuk melakukan pengelolaan hubungan dengan pelanggan yang dikendalikan oleh Customer Journey Assistant.

\section{Strategi Online CRM}

Strategi pertama adalah Attract! Atau Promosi Banner. Kalakota dan Robinson membahas tahap ini sebagai tahap dimana perusahaan berusaha untuk mendapatkan pelanggan konsumen baru atau pelanggan baru didapatkan dengan memberikan informasi atau promosi mengenai produk, inovasi, dan pelayanan yang dapat menarik hati para pelanggan baru tersebut (Kalakota \& Marcia Robinson, 2001). Perusahaan menggunakan media sosial Facebook yang terintegrasi dengan Instagram untuk dapat membuat iklan yang muncul pada sosial media Instagram target market mereka. Contohnya seperti pada gambar berikut: 


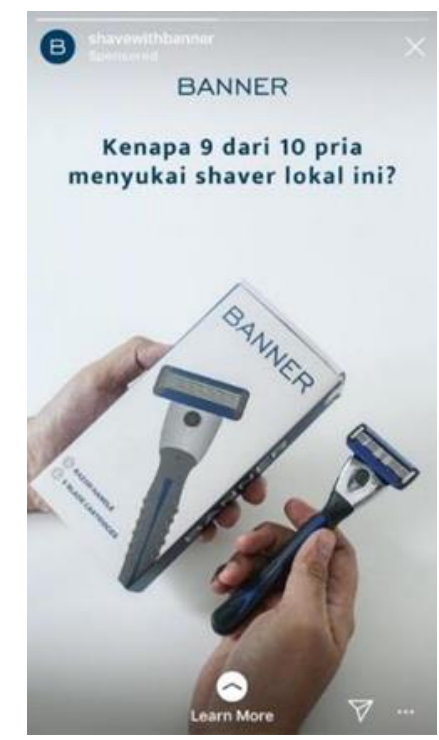

Sumber: Dokumen Perusahaan

Gambar 1. Iklan Instagram Banner

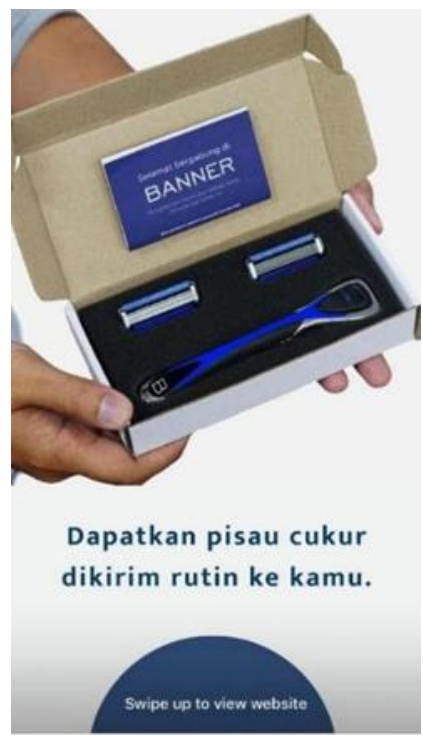

Sumber: Dokumen Perusahaan

\section{Gambar 2. Iklan Instagram Banner}

Iklan ini muncul pada fitur Instagram stories dan Instagram sponsored yang biasanya muncul pada bagian iklan yang disediakan oleh pihak Instagram. Iklan ini merupakan penerapan dari 2 prinsip konten yang selalu dibuat oleh Direktur Utama dibantu Content Specialist. Yang pertama adalah prinsip memberikan konten yang informatif dan yang kedua adalah prinsip memberikan konten yang entertaining.

Prinsip entertaining bertujuan untuk memberikan kesan bahwa brand ini bukanlah suatu brand yang terlalu serius tentang pisau cukur, personal care, men's grooming, atau produk kecantikan wajah pria saja. Namun juga membuat konten Instagram yang mampu untuk menghibur pelanggan 
dari media sosial. Dari segi konten yang informatif, konten yang informatif haruslah dapat memberikan kualitas informasi yang baik hal ini dapat dilihat dari segi kebaharuan informasi, keakuratan informasi, dan kelengkapan informasi yang diberikan pada pelanggan (Kim \& Park, 2013). Konten informatif yang diproduksi oleh PT. AWP adalah konten yang dapat menarik calon pelanggan-pelanggan Banner dan mengutamakan kelengkapan informasi yang sampai pada target.

Gambar 1 dan gambar 2 adalah contoh konten iklan pada fitur Instagram sponsored agar bisa langsung diarahkan ke website bannershave.com untuk informasi lebih mendetil. Selain itu berbagai promosi barang dan diskon produk juga diberikan kepada pelanggan untuk dapat melakukan recurring produk pisau cukur Banner. Tak hanya selalu informasi tentang produk yang disampaikan kepada pelanggan dan calon pelanggan namun juga tips-tips mencukur dan berbagai trivia tentang cukuran janggut dan kumis juga dilakukan.

Cara promosi atau Attract! dengan menggunakan Instagram inipun cukup memberikan pengaruh kepada pelanggan dan perusahaan. Dari hasil wawancara mendalam 5 pelanggan setia Banner yang setiap bulannya selalu melakukan recurring produk pisau cukur ini mereka mengaku mengetahui produk Banner ini dari Instagram.

Strategi kedua adalah menangkap data pelanggan. Data telah menjadi sebuah aset berharga dan penting dalam ranah pemasaran dan CRM. Karena melalui penggunaan data sebuah hubungan dengan pelanggan bisa dilacak, analisa, dan bisa dikembangkan (Fill \& Turnbull, 2016).

Banyaknya informasi mengenai data ini telah muncul di dunia digital dan dikenal dengan sebutan "Big Data". Menurut Nunan \& Di Domenico dalam (Fill \& Turnbull, 2016) salah satu dampak dari penggunaan Big Data dalam bidang marketing adalah nilai tambah dalam bidang penjualan dengan menggunakan wawasan dari konsumen yang lebih efektif. Begitupun dengan PT. AWP, untuk mendapatkan pelanggan baru mereka juga memanfaatkan Big Data yang dimiliki oleh dari Facebook Pixels. Mereka menggunakan data dari yang sudah mereka punya dan kemudian dipadukan dengan data yang ada pada Facebook Pixels sehingga mereka bisa untuk menemukan berbagai prospek pelanggan atau target market yang sesuai dengan target yang dituju oleh perusahaan.

Dari tahap ini pula perusahaan dapat menentukan strategi online CRM, bagaimana strategi yang sesuai berdasarkan database yang telah mereka miliki. PT. AWP Sebagai produsen pisau cukur Banner memanfaatkan data dari pelanggan yang sudah ada untuk mengidentifikasi jenis pelanggan, sehingga dengan bantuan Facebook Pixels nantinya perusahaan dapat memberikan dan membuat iklan yang lebih efektif.

Strategi ketiga adalah membangun relasi dengan pelanggan. Setelah menyatukan data menjadi satu dalam database barulah dilakukan processing data untuk meningkatkan praktik online CRM dan membangun hubungan dengan pelanggan. Untuk memahami dan mengenal pelanggan menurut (Artaya, 2013) bisa dilakukan dengan memahami bahwa kehidupan pelanggan adalah kehidupan perusahaan sehingga penting untuk perusahaan bisa memberikan pelayanan yang lebih kepada pelanggan. Memberikan pelayanan lebih kepada pelanggan ini salah satu elemen keberhasilannya adalah dengan memberikan kepuasan pelanggan dimana faktor-faktornya adalah pendekatan pertama dengan pelanggan, mutu informasi yang diberikan, dan dampak (outcome) yang diterima oleh pelanggan. 
Online CRM bukan hanya mendapatkan data dan memanfaatkan teknologi untuk membangun hubungan dengan pelanggan saja, namun online CRM juga digunakan untuk melengkapi budaya pelanggan (Chafey \& Smith, 2008). Dengan melengkapi diri dalam budaya pelanggan dapat membuat perusahaan lebih mudah untuk menjangkau pelanggan. Berdasarkan hasil temuan data, perusahaan membangun hubungan awal/pendekatan pertama dengan pelanggan-pelanggannya menggunakan customer service mereka yang bernama Siska. Pada setiap pembelian pertama yang dilakukan oleh pelanggan, Siska akan menghubunginya melalui Whatsapp dan akan melakukan perkenalan diri untuk bisa menjelaskan bahwa Siska ini akan membantu untuk membuat pengiriman sesuai dengan keinginan pelanggan dan juga membantu jika ada masalah atau kesulitan dalam pengiriman. Inilah yang dilakukan oleh Tesha Rizkia sebagai pemangku jabatan dari Customer Journey Assistant Di awal permulaan memulai pembicaraan dengan menggunakan Siska ini, Siska juga berusaha untuk memberikan penjelasan mengenai nomor pemesanan dan kapan estimasi barang sampai di tangan pelanggan.

Perusahaan berusaha untuk dapat membangun hubungan awal ini dengan memberikan pemahaman dan penjelasan apa saja yang didapat dengan berlangganan produk pisau cukur Banner. Mulai dari mereka mendapatkan service quality yang baik dan ramah, memberikan pemahaman kemudahan dan kenyamanan berlangganan serta manfaat berlangganan, memberikan ucapan ulangtahun dan promo khusus pelanggan yang berulangtahun, dan memberikan mystery gift seperti satu bungkus $1 / 4$ kilo kopi atau natural soak salt untuk pembersih kaki pada pembelian pertama pelanggan. Harapan utama yang ingin dicapai dari segala usaha untuk membangun hubungan awal ini adalah agar kedepannya para pengguna Banner ini sendiri bisa menjadi suatu komunitas yang dapat saling menyayangi produk pisau cukur Banner. Harapan inilah yang membuat perusahaan termotivasi untuk bisa memberikan nilai yang lebih dari ekspektasi yang ada dibenak pelanggan.

Strategi keempat adalah membuat pelanggan merasa penting. Pada tahap ini perusahaan dapat meningkatkan nilai pelanggan. Perusahaan sebagai produsen suatu produk berusaha menjalin hubungan dengan pelanggan melalui pemberian pelayanan yang baik kepada pelanggannya (Kalakota \& Marcia Robinson, 2001). Perusahaan bisa melakukan pendekatan-pendekatan yang disarankan oleh Chaffey dan Smith dengan memberikan penawaran (promo), hadiah, potongan harga, dan informasi serta pengalaman yang menunjukkan kepada pelanggan bahwa perusahaan benar-benar dapat memberikan kemudahan dan kenyamanan bagi pelanggan (Chafey \& Smith, 2008).

Berdasarkan data yang ditemukan, PT. AWP mengutamakan suara dari para pelanggannya (voice of customer) untuk dapat meningkatkan nilai dengan pelanggan-pelanggannya. Voice of customer ini tidak selalu harus mengenai kebaikan atau nilai plus dari produk Banner bisa juga mengenai kekurangan atau nilai minus dari produk Banner. Bagi perusahaan voice of customer penting dan lebih berarti dibanding dengan suara dari pihak perusahaan itu sendiri. Hal ini dikarenakan sistem berlangganan ini mengutamakan apa yang pelanggan tersebut butuhkan karena mereka sudah memberikan pembayaran setiap paket shaveplan yang sudah dipilihnya. Selain itu voice of customer sendiri penting untuk perusahaan untuk membuat ruang pengembangan (room of improvement) yang dibutuhkan oleh perusahaan untuk dapat mengembangkan kualitas produk. Baik dari segi produk, pelayanan, dan service yang diberikan oleh perusahaan.

Dari perspektif pelanggan-pelanggannya sendiri, 4 dari 5 pelanggan mengaku bahwa mereka merasa menjadi bagian penting dari perusahaan ini karena mereka selalu diingatkan ketika ada jadwal pengiriman ulang pisau cukur (recurring), lalu diberikan hadiah-hadiah yang tak terduga 
seperti kopi, pomade, dan natural salt soak. 1 orang yang merasa tidak menjadi bagian penting dari perusahaan ini sendiri karena ia merasa bahwa selama ini tidak ada yang spesial dari Banner dalam melakukan pelanggan-pelangganya. Dalam konotasi yang positif, Ia merasa Banner sama saja seperti yang lainnya dalam melakukan sistem berlangganan.

Strategi kelima adalah mempertahankan pelanggan. Berdasarkan hasil temuan data yang dilakukan oleh peneliti, perusahaan berusaha untuk dapat mempertahankan pelangganya dengan menggunakan dan meningkatkan keuntungan-keuntungan yang didapat dari berlangganan produk pisau cukur Banner. Salah satunya adalah ketika Banner akan melakukan launching produk baru maka pelanggan-pelanggan yang sudah lama ini akan mendapatkan informasi dan mereka berhak untuk dapat mencoba gratis produk-produk tersebut. Selain itu perusahaan juga tetap melakukan potongan-potongan harga (promo diskon) yang diberikan khusus di setiap pembelian pelanggan. Promo ini dinamai dengan nama Mulus yang selalu ada disetiap pembelian produk Banner.

Selain itu, perusahaan juga terus menjalankan konsep untuk tetap mengingatkan pelanggan mengenai jadwal recurringnya masing-masing. Dan agar pelanggan tetap dapat memberikan keuntungan bagi perusahaan, ketika mereka tidak membeli ulang pisau cukur walaupun sudah waktunya untuk membeli perusahaan berusaha untuk mengarahkannya pada berbagai barang lain yang dimiliki oleh Banner. Berbeda dengan pelanggan yang sudah pernah berlangganan dan sudah lama tidak melakukan pembelian ulang. Perusahaan biasanya melakukan promosi dan menyampaikan broadcast message lewat Siska kepada seluruh pelanggan agar mereka kembali dapat berlangganan dengan produk pisau cukur Banner lewat promo-promo yang diberikan.

Pelanggan-pelanggan Banner pun menyatakan bahwa mereka bertahan menggunakan Banner sendiri karena mereka senang dengan konsep kepraktisan dalam berlangganan yang diangkat oleh Banner. Ditambah mereka senang karena selalu diingatkan oleh Siska ketika jadwal recurringnya sudah masuk masa jatuh tempo atau sudah masa pembelian ulang karena mereka sendiri seringkali lupa akan hal tersebut. Serta mereka hanya perlu menunggu barang sampai dirumah dan pisau cukur langsung siap dipakai.

\section{PENUTUP}

Berdasarkan penelitian yang dilakukan mengenai analisis strategi online customer relationship management (CRM) produk pisau cukur Banner, dapat ditarik kesimpulan bahwa PT. AWP sebagai produsen pisau cukur Banner menerapkan online CRM dengan memanfaatkan berbagai teknologi yang dapat mendukung dengan kondisi dari target konsumennya. PT. AWP sebagai perusahaan penyedia pisau cukur dengan sistem berlangganan menggunakan strategi online CRM yang sesuai dengan keadaan marketing 4.0 dimana saat ini teknologi seperti artificial intelligence juga dibutuhkan untuk meningkatkan performa dan kualitas produk. Kualitas dan performa ini ditingkatkan oleh perusahaan dengan mengembangkan pelayanan yang diberikan kepada pelanggan (customer service) untuk dapat meningkatkan hubungan dengan pelanggan (customer relations) dengan membuat sebuah chatbot. PT. AWP sadar bahwa produk yang mereka jual bisa sekali dikalahkan oleh produk sejenis sehingga mereka meningkatkan performa dan kualitas produknya dari segi pelayanan untuk menimbulkan kedekatan pada setiap pelanggannya.

Generasi milenial sebagai target market dari produk Banner merupakan generasi yang memiliki ciri khas tertentu. Seperti yang dikatakan oleh Bencsik \& Machova dalam (Putra, 2018) dan ditambahkan menurut (Avisha, 2018) bahwa generasi milenial ini memiliki sifat-sifat yang tidak 
loyal pada suatu produk dan memiliki karakter instant online buying. Generasi ini menggunakan teknologi setiap hari bahkan sudah menjadi bagian dari hidupnya. mereka juga memiliki perilaku yang berkeinginan untuk mandiri, tidak menghormati tradisi, dan mencari bentuk-bentuk pengetahuan. Sehingga generasi ini bukanlah generasi yang mementingkan suatu produk jika dikaitkan dengan budaya atau sebuah tradisi.

Hal inipun menjadi tantangan untuk Banner agar dapat mendapatkan hati dari para target marketnya ini. Namun pada kasusnya dalam studi atau penelitian ini mereka mampu untuk dapat mengelola pelanggan-pelanggannya yang merupakan generasi milenial. Mereka mengadaptasikan apa yang dikatakan oleh (Chafey \& Smith, 2008) bahwa online CRM juga harus dapat melengkapi budaya pelanggan.

Sadar akan hal tersebut, mereka membuat program online CRM bernama Siska yang merupakan kepanjangan dari Sistem Kepuasan Anda/Banner. Siska digunakan untuk dapat melengkapi implementasi dari online CRM Banner yang dimulai dari tahap Attract! atau promosi yang menggunakan Instagram yang sudah terintegrasi dengan Facebook Pixels dan Google Pixels. Menangkap data pelanggan yang berhubungan dengan kepentingan perusahaan dan penjualan seperti nama, nomor telepon, alamat, paket berlangganan dan berbagai data pribadi lainnya dengan mengisi data pada web bannershave.com. Sehingga Siska mampu untuk memaksimalkan peran dan menyempurnakan implementasi online CRM ini pada tahap mengelola hubungan dengan pelanggan mulai dari membangun hubungan dengan pelanggan, merangkul pelanggan (embrace) atau membuat pelanggan menjadi bagian penting dalam perusahaan, dan mempertahankan pelanggan (golden handcuffs).

Siska merupakan sistem customer service yang digunakan untuk mengelola dan meningkatkan hubungan dengan pelanggan. Siska merupakan artificial intelligence yang dibuat oleh perusahaan berupa chatbot text-to-text bot dengan format convertion oriented dan memiliki identitas diri berupa wanita berusia sekitar 25 tahun. Siska adalah persona yang dibuat di aplikasi Whatsapp dan Line dan digunakan menjadi palang pintu pertama informasi masuk dan keluar perusahaan. Siska dikendalikan oleh Customer Journey Assistant sebagai "tangan kanan" dari Direktur Operasional yang bertanggung jawab pada setiap program CRM yang dilakukan PT. AWP.

Siska ini direncanakan karena melihat dari kondisi-kondisi yang dialami dan riset yang dilakukan oleh perusahaan. Diantaranya, PT. AWP menyadari dengan target market yang dipilih dan pelanggan mereka merupakan laki-laki generasi milenial yang memiliki perilaku tidak loyal terhadap barang bermerk yang tidak terkenal serta pelanggan-pelanggan Banner yang lebih sedikit memberikan respon/feedback mengenai produk dan perusahaan ketika Customer Journey Assistant dipegang oleh laki-laki (Dimas). Dari 2 permasalahan ini PT. AWP akhirnya membuat sistem persona seorang wanita bernama Siska. Tujuan perusahaan membuat Siska ini agar mampu untuk mengelola hubungan dengan pelanggan yang mayoritas adalah laki-laki. Siska utamanya diaplikasikan pada Whatsapp dan dipegang oleh pemegang jabatan dari Customer Journey Assistant. Siska dibuat menjadi sebuah persona yang tidak memperlihatkan identitas asli dari pemegang jabatan dari Customer Journey Assistant agar nantinya ketika pemegang jabatan dari Customer Journey Assistant berganti orang siapapun yang mengendalikan Siska dan tidak perlu untuk membangun ulang hubungan dengan pelanggan. Sehingga hal ini memudahkan perusahaan dan pelanggan untuk meningkatkan dan mengelola hubungan dengan pelanggan. 
Perusahaan memulai tahapan online CRM ini dari Attract! atau promosi kemudian menangkap data pelanggan (capturing data) lalu membangun hubungan dengan menggunakan database yang sudah dimiliki dari tangkapan data pada tahap sebelumnya. Kemudian membuat pelanggan merasa mereka adalah hal penting bagi perusahaan supaya mereka dapat merasa sangat dihargai oleh perusahaan sehingga mereka mau untuk bertahan menggunakan produk tersebut (golden handcuffs).

Dalam melakukan tahap promosi, PT. AWP mayoritas menggunakan Instagram untuk membuat iklan produk yang bisa langsung muncul pada fitur-fitur yang ada di Instagram setiap target market dan pelanggan mereka. Hal ini dilakukan untuk membuat brand awareness pada produk pisau cukur Banner dengan memanfaatkan Instagram Story, Instagram Sponsored, serta Feeds pada Instagram. Setelah itu ketika pelanggan mulai ingin melakuakn pembelian, mereka diarahkan untuk mendaftarkan diri di website bannershave.com agar perusahaan dapat menangkap data-data pelanggan mulai dari alamat, tanggal lahir, pilihan paket langganan pisau cukur dan data pribadi lainnya. Kemudian PT. AWP berusaha untuk membangun hubungan pelanggan dengan memberikan ucapan ulangtahun dan promo khusus bagi setiap pelanggan yang berulangtahun. Selain itu, perusahaan juga berusaha untuk memberikan mystery gift di awal pembeliannya untuk menimbulkan kesan nyaman bagi pelanggan. PT. AWP tidak hanya ingin membuat kesan nyaman dan keramahan bagi pelanggan namun PT. AWP juga ingin mengembangkan Banner seperti komunitas. Sehingga mereka juga memberikan empati dan simpati kepada pelangganpelanggannya yang sedang mengalami masalah seperti pada kasus Daddy Tjeuw (salah satu pelanggan Banner). Selain itu mereka selalu mengingatkan jadwal pengiriman ulang agar pelanggan tidak perlu khawatir dan memikirkan ketika pisau cukurnya sudah tumpul. Bukan hanya untuk memberikan kesan empati dan simpati namun hal ini dilakukan oleh perusahaan untuk membuat pelanggan mereka merasa menjadi bagian penting dari PT. AWP dan juga Banner. PT. AWP mulai dari Komisaris Utama hingga Customer Journey Assistant mau untuk turun tangan menemui pelanggan agar mereka merasa menjadi komunitas dari Banner hal ini membuat perusahaan menjadi lebih bisa mendengar apa yang dibutuhkan oleh pelanggan (feedback). Selain itu feedback pelanggan juga dikumpulkan dengan menanyakan mengenai kepuasan pelanggan dan apa yang sedang dibutuhkan oleh pelanggan. Cara ini dilakukan oleh perusahaan untuk dapat membuat para pelanggannya menjadi loyal dengan produk pisau cukur ini (golden handcuffs).

Hasil program online CRM dengan menggunakan Siska ini pun cukup menarik. Salah satu pelanggan mereka pun menjadi investor untuk perusahaan ini agar perusahaan ini tetap berjalan, berkembang, dan bertahan di industri pisau cukur di Indonesia. Pelanggan tersebut berhasil menjadi investor karena kedekatan yang dibangun oleh direksi dan karyawan perusahaan dan keramahan yang dibangun oleh perusahaan dari program Siska. Selain itu, program online CRM ini membuat perusahaan bisa memproduksi 4 produk lain yang dapat membantu hasil mencukur dari hasil pengumpulan kepuasan dan feedback pelanggan.

\section{DAFTAR PUSTAKA}

Armstrong, G., \& Kotler, P. (2012). Marketing: An Introduction (12th Edition). New Jersey: Pearson.

Artaya, I. P. (2013). Wiraniaga - Membangun Jaringan Penjualan (Issue November). Surabaya: Naratoma University Press. 
Avisha, I. M. (2018). Perbedaan Minat Beli Online Generasi X, Y, dan Z [Universitas Sanata Dharma].

Chafey, D., \& Smith, P. R. (2008). Emarketing Excellence: Planning and Optimizing your Digital Marketing 4th Edition (3rd Edition). Oxford: Butterworth-Heinemann.

D.A.S, G., Illankoon, I. M. C. S., \& Ranadewa, T. (2016). A Literature review on marketing Green Buidlings ; 4C Marketing mix approach. May.

Daymon, C., \& Holloway, I. (2002). Qualitative Research Methods in Public Relations and Marketing Communications (Psychology).

Faiza, A., \& Firda, S. J. (2018). Arus Metamorfosa Milenial (Pertama). Kendal: Penerbit Ernest.

Fill, C., \& Turnbull, S. (2016). Marketing Communications Discovery, Creation and Conversations. London: Pearson.

Fitrah, M., \& Luthfiyah. (2017). Metodologi Penelitian; Penelitian Kualitatif, Tindakan Kelas \& Studi Kasus. Sukabumi: Jejak Publisher.

Gambhir, P. (2019). Review of Chatbot Design and Trends. Indira Gandhi Delhi Technical University for Women (IGIT).

Hidayatullah, S., Waris, A., \& Devianti, R. C. (2018). Perilaku Generasi Milenial dalam Menggunakan Aplikasi Go-Food. Jurnal Manajemen Dan Kewirausahaan, 6(2), 240-249.

Kalakota, R., \& Marcia Robinson. (2001). E-Business 2.0 Roadmap For Success. Amerika Serikat: Addison-Wesley.

Kim, S., \& Park, H. (2013). Effects of various characteristics of social commerce (s-commerce) on consumers' trust and trust performance. International Journal of Information Management, 33(2), 318-332.

Meyer, J., \& Gremler, D. D. (2015). Customer Service. Wiley Encyclopedia of Management.

Priansa, D. J. (2017). Komunikasi Pemasaran Terpadu: Pada Era Media Sosial. Bandung: Pustaka Setia Bandung.

Putra, Y. S. (2018). Theoritical Review. 1952, 123-134.

Rangkuti, F. (2006). Measuring Customer Satisfaction: Gaining Customer Relationship Strategy Teknik Mengukur Dan Strategi Meningkatkan kepuasan Pelanggan \& Analisis Kasus PLNJP. Jakarta: Gramedia Pustaka Utama.

Rinda, W. (2015). Consumer Behavior: Tipe-tipe Pembeli Berdasarkan Gender., diakses 22 Februari 2020,

dari https://www.kompasiana.com/wahyurinda/552a1628f17e61de57d623aa/consumer- 
behavior-tipetipe-pembeli-berdasarkan-gender

Sarwono, R. (2018). Memahami 10 Perilaku Konsumen Milenial., diakses 14 Januari 2020, dari Sarwono.My.Id. https://sarwono.my.id/lifestyle/memahami-10-perilaku-konsumen-milenial

Strauss, J., \& Frost, R. (2014). E-Marketing (7th Edition (ed.)). London: Pearson.

Terziev, V., Banabakova, V., \& Georgiev, M. (2018). Developing Customer Service Standards. International Conference Knowledge, 42(4), 1. 